\title{
Find the Moral
}

$\mathrm{O}$ nce upon a time the animals decided they must do something decisive if they were ever to solve the problems created by the growing complexity of their society. They set up a working party and, in due course, the working party reported back that in their view, taking all circumstances into consideration, a school should be set up. A second working party was then appointed to consider this recommendation and in due course their report appeared as well. This agreed with the first report, and recommended that the school curriculum should consist of Running, Climbing, Swimming and Flying, research studies having shown that these were the basic behaviour patterns of most animals. They also recommended that every pupil should be encouraged to obtain passes in all subjects before leaving school. And so it was decided, and the school opened its gates for the first time.

The duck proved to be excellent at swimming, better in fact than his teacher. He also did well in flying, but he was a very awkward runner. Since he was poor in this subject a remedial programme was devised which gave him extra time to devote to running. He had, of course, less time to spend on swimming but since the objective was a well-rounded duck his teachers thought that a small price to pay. His running teacher was unsparing, and kept the duck at it until his webbed feet were so badly damaged that he became only average at swimming. But average was acceptable at this school so nobody worried about that except the duck.

The rabbit started at the top of the ladder in running and was a passable swimmer, but found the core requirement in tree climbing too much for him. He developed a bad case of school phobia, and only attended on days when running was the subject of instruction. Eventually he reached the leaving age and left, ignoring the advice of his teachers that a rabbit that could neither fly nor climb was unlikely to amount to very much. In later years, after a good deal of struggling and hard work, the rabbit became a great business success and was often invited to sit on advisory committees and give end-of-year addresses. On these occasions he would always boast that he was a self-made rabbit. His own children, of course, went to a private school.

The possum, unlike the rabbit, had no problems with climbing but had great difficulty in the flying class, where the teacher believed in formal methods and insisted that everyone start from the ground and not the tree-tops. The possum however, was very anxious to learn and kept at his flying lessons, practising after school at every opportunity. In the final examination he managed a bare pass in flying. Unfortunately, he failed climbing and had to repeat that course.

The kea was the school's worst discipline problem for in the climbing class he beat all the others to the top of the tree used for examination purposes in this subject - but he insisted on using his own methods to get there. He was placed in a special class.

At the end of the first year only one student obtained passes in all subjects and this was an eel who could swim well, run a little and who had just managed to reach the minimum standards in climbing and flying. He was made Dux and given a university scholarship.

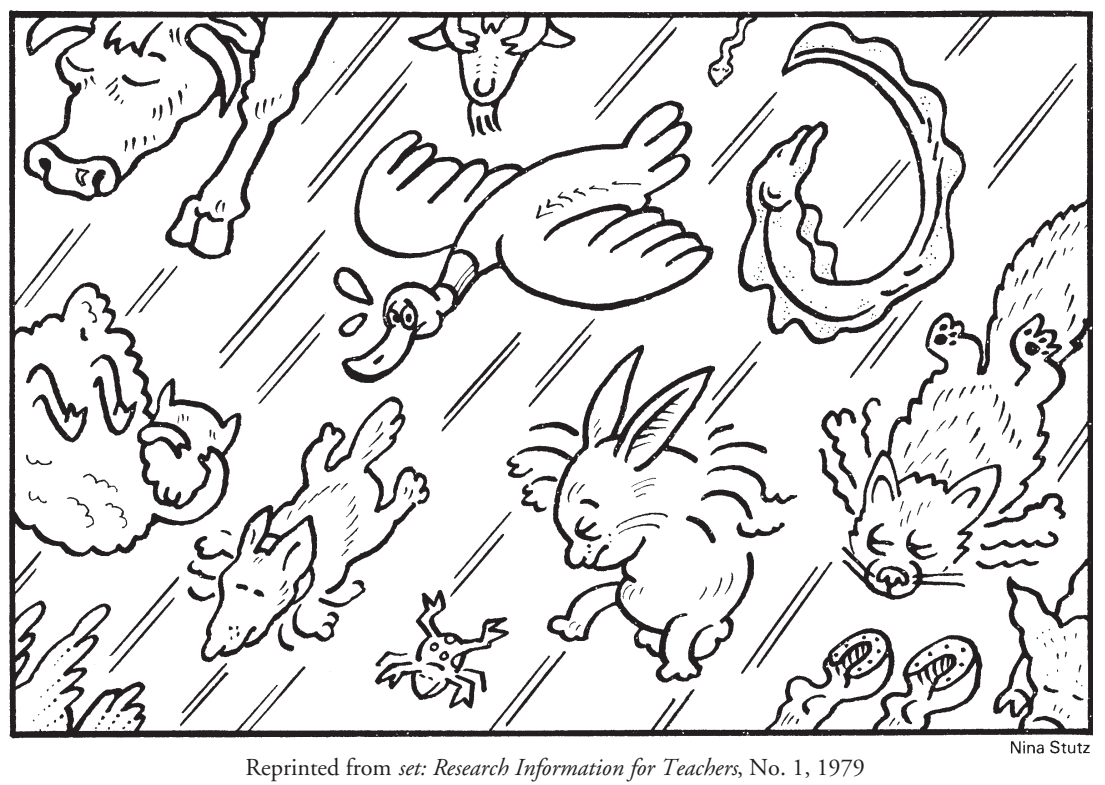

